\title{
Low Mitogenic Activity of Synthetic Lipid A Analog, 2,3-Acyloxyacylgalactosamine-4-phosphate, in Cultured Murine Splenocytes
}

\author{
Tadayori Shimizu,* Toshiyuki Masuzawa, Yoshihisa Iwamoto, Yasutake Yanagihara, \\ Kenji Sano, Kiyoshi IKeda, and Kazuo ACHIwa \\ University of Shizuoka, School of Pharmaceutical Sciences, Yada 52-1, Shizuoka 422, Japan. Received July 13, 1992
}

\begin{abstract}
The mitogenicity of chemically synthesized lipid A analogs, 2,3-acyloxyacylglucosamine-4-phosphate (A-103) and 2,3-acyloxyacylgalactosamine-4-phosphate (A-113), was compared. Synthetic lipid A analogs of the disaccharide-type (506), the monosaccharide-type (A-103) suspended in RPMI-1640 medium supplemented with triethylamine, and Salmonella typhimuirium LT-2 lipopolysaccharide (LPS) were capable of increasing the incorporation of $\left[{ }^{3} \mathrm{H}\right]$ thymidine into splenocytes of C57BL/6 mice at various doses ranging from 1.0 to $100 \mu \mathrm{g} / \mathrm{ml}$. However, the mitogenic activity of A-113 at these doses was markedly weaker than the activity of the above materials. When the A-103 and A-113 were suspended in RPMI-1640 medium supplemented with ethanol, the mitogenic activity of A-113 also showed lower activity than that of A-103 in the splenocytes of C57BL/6 mice. These findings indicate that the mitogenic activity of synthetic lipid $A$ of the monosaccharide-type is affected by a kind of composed sugar.
\end{abstract}

Keywords lipid A analog; lipopolysaccharide; mitogenicity

Lipid $\mathrm{A}$ is known to be responsible for various biological activities of the lipopolysaccharide (LPS) of gram-negative bacteria. ${ }^{1)}$ Various lipid A analogs of the monosaccharidetype have been synthesized, and these compounds showed many of the biological activities of LPS. ${ }^{2)}$

Bacterial LPS usually consists of a glucosaminyl- $\beta$-Dglucosamine as a backbone sugar of lipid A. ${ }^{1}$ The examination of the biological activity of synthetic lipid A analogs of the monosaccharide-type possessing other kinds of sugar is therefore of interest.

Here, we examined the differences of mitogenicity between two synthetic lipid A analogs, 2,3-acyloxyacylglucosamine-4-phosphate (A-103) and 2,3-acyloxyacylgalactosamine-4-phosphate (A-113), in the splenocytes of C57BL/6 mice.

\section{Materials and Methods}

Test Materials Compound A-103 was synthesized from D-glucosamine- $\mathrm{HCl}$ as described in a previous paper. ${ }^{3)} \mathrm{A}-113$ was synthesized from D-galactosamine- $\mathrm{HCl}$ in nine steps, and detailed methods will be published elsewhere. The chemical structures of these compounds are shown in Fig. 1. Each compound was suspended in RPMI-1640 medium (Nissui Pharmaceutical Co., Ltd., Tokyo) supplemented with $0.1 \%$ triethylamine $(\mathrm{v} / \mathrm{v})$ or $5 \%$ ethanol $(\mathrm{v} / \mathrm{v})$ and sonicated for $20-30 \mathrm{~s}$. For use, the stock solutions were serially diluted to the required concentrations with RPMI-1640 medium. The final concentration of triethylamine or ethanol in the tested solutions was less than $0.01 \%$ or $0.25 \%$, respectively. Synthetic lipid A (506) of the Escherichia coli-type was purchased from Dai-ichi Pure Chemicals Co., Tokyo. The natural LPS of $S$. typhimurium LT-2 was isolated from dried cells by the hot phenol-water method ${ }^{4)}$ and purified
A-103

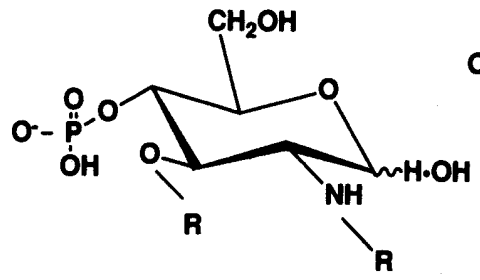

A-113

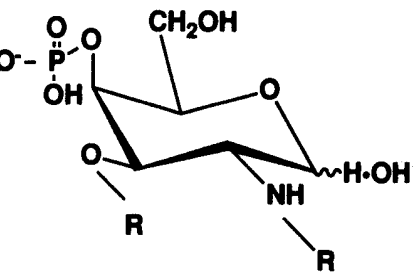

Fig. 1. Chemical Structures of A-103 and A-113 $\mathrm{R}=\mathrm{C}_{14}-\mathrm{O}-\mathrm{C}_{14} ;(R)$-3-tetradecanoyloxytetradecanoyl. by ribonuclease (RNase, Sigma Chemical Co., St. Louis, MO, U.S.A.) and ultracentrifugation $(105000 \times \mathrm{g}, 1 \mathrm{~h})$.

Animals Male C57BL/6 mice, 5 weeks old, were purchased from the Japan SLC Co. (Hamamatsu).

Mitogenicity Test Mitogenicity was tested using murine spleen cells. The splenocytes were suspended in RPMI-1640 medium supplemented with $10 \%$ fetal bovine serum (Irvine Scientific, Co., CA, U.S.A.). One-tenth milliliter $\left(5 \times 10^{5}\right.$ cells $)$ of the cell suspension and $0.1 \mathrm{ml}$ of a suspension of a test compound or reference materials were placed in a 96-well microplate (Falcon 3072, Becton Dickinson Labware, Oxnard, CA, U.S.A.). The plate was incubated at $37^{\circ} \mathrm{C}$ for $64 \mathrm{~h}$ in an atmopshere of $5 \% \mathrm{CO}_{2} / 95 \%$ air. After the addition of $9.25 \mathrm{kBq}$ of $\left[{ }^{3} \mathrm{H}\right]$ thymidine $(\mathrm{New}$ England Nuclear, Corp., Boston, MA. U.S.A.) to each well, the plate was further cultivated for $16 \mathrm{~h}$. Splenocytes were harvested with an automatic cell harvester. Radioactivity uptaken by the cells was measured with a liquid scintillation counter (LSC-3100, Aloka Co., Tokyo). Results were expressed as the mean counts per min (cpm) of triplicate wells per a group of each concentration.

Statistical Analysis The significance of the results was analyzed using the Student's $t$ test. Probability values of less than 0.05 were considered significant.

\section{Results and Discussion}

The results of the mitogenic assay of the compounds A-103 and A-113, which were suspended in RPMI-1640 medium supplemented with triethylamine, in the splenocytes of C57BL/6 mice are shown in Table I.

The mitogenic activity of compound A-103 was observed at various doses of 1.0 to $100 \mu \mathrm{g} / \mathrm{ml}$, but was weaker than that of 506, S. typhimurium LPS. The compound, A-113, also possessed weak mitogenic activity at doses of 5,10 and $25 \mu \mathrm{g} / \mathrm{ml}$, but exhibited lower potency than A-103. These results were reproducible.

Next, we added 5\% ethanol to a stock solution of A-103 and A-113, and the suspensions were sonicated. As shown in Table II, the mitogenic activity of A-113 was lower than that of A-103 at various doses ranging from 5.0 to $50 \mu \mathrm{g} / \mathrm{ml}$. Therefore, under the conditions involving ethanol or triethylamine supplementation, the finding that the galactosamine-4-phosphate (A-113) has lower mitogenicity than the glucosamine-4-phosphate (A-103) was also observed.

The reason compound A-113 resulted in a lower activity than compound A-103 is not clear, but the difference of the potency between the compounds regarding mitogenic 
TABLE I. Mitogenic Activity of Synthetic Lipid A Analogs in RPMI1640 Medium Supplemented with Triethylamine on Cultured Splenocytes of C57BL/6 Mice in Vitro

\begin{tabular}{lrcc}
\hline \hline & & \multicolumn{2}{c}{$\left[{ }^{3} \mathrm{H}\right]$ Thymidine uptake } \\
\cline { 3 - 4 } Materials tested & $\begin{array}{c}\text { Dose } \\
(\mu \mathrm{g} / \mathrm{ml})\end{array}$ & Mean cpm \pm S.D. & S.I..$^{a)}$ \\
\hline A-103 & 100 & $13369 \pm 1069$ & $5.9^{b)}$ \\
& 50 & $19018 \pm 4400$ & $8.4^{b)}$ \\
& 25 & $15485 \pm 1306$ & $6.8^{b)}$ \\
& 10 & $18877 \pm 2255$ & $8.3^{b)}$ \\
& 5 & $14523 \pm 2010$ & $6.4^{b)}$ \\
A-113 & 1 & $10517 \pm 866$ & $4.6^{b)}$ \\
& 100 & $2032 \pm 191$ & 0.9 \\
& 50 & $3086 \pm 400$ & 1.4 \\
& 25 & $3963 \pm 514$ & $1.7^{b)}$ \\
506 & 10 & $4580 \pm 697$ & $2.0^{b)}$ \\
& 5 & $3963 \pm 571$ & $1.7^{b)}$ \\
S. typhimurium & 1 & $3072 \pm 844$ & 1.4 \\
LT-2 LPS & 50 & $39421 \pm 5200$ & $17.4^{b)}$ \\
Control (no addition) & 10 & $40607 \pm 5315$ & $17.9^{b)}$ \\
& 50 & $34384 \pm 2041$ & $15.2^{b)}$ \\
& 10 & $47663 \pm 1687$ & $21.0^{b)}$ \\
& & $2268 \pm 156$ & 1.0 \\
\hline
\end{tabular}

a) stimulation index (S.I.) = experimental cpm/control cpm. b) Statistically significant compared to control $(p<0.05)$.

TABLE II. Mitogenic Activity of Synthetic Lipid A Analogs in RPMI1640 Medium Supplemented with Ethanol on Cultured Splenocytes of C57BL/6 Mice in Vitro

\begin{tabular}{lccc}
\hline \hline \multirow{2}{*}{ Materials tested } & $\begin{array}{c}\text { Dose } \\
(\mu \mathrm{g} / \mathrm{ml})\end{array}$ & \multicolumn{2}{c}{$\left[{ }^{3} \mathrm{H}\right]$ Thymidine uptake } \\
\cline { 3 - 4 } & & Mean cpm \pm S.D. & S.I. ${ }^{a)}$ \\
\hline A-103 & 50 & $13301 \pm 2485$ & $5.1^{b)}$ \\
& 25 & $12840 \pm 1741$ & $4.9^{b)}$ \\
& 10 & $10201 \pm 2531$ & $3.9^{b)}$ \\
A-113 & 5 & $4652 \pm 411$ & $1.8^{b)}$ \\
& 50 & $6484 \pm 2880$ & 2.5 \\
& 25 & $3124 \pm 576$ & 1.2 \\
S. typhimurium & 10 & $1982 \pm 100$ & 0.8 \\
LT-2 LPS & 5 & $2599 \pm 178$ & 1.0 \\
Control (no addition) & 10 & $56857 \pm 2238$ & $21.6^{b)}$ \\
& & $2628 \pm 660$ & 1.0 \\
\hline
\end{tabular}

a)

a) See legend $a$ ) in Table I. b) Statistically significant compared to control ( $p<$ $0.05)$. activity is presumably associated with the difference in solubility.

Lipid A of bacterial LPS consists of a glucosaminyl- $\beta$-Dglucosamine disaccharide as a backbone sugar. ${ }^{1)}$ However, galactosamine phosphate as a backbone sugar of lipid A has not been found in the LPS of any bacteria. There are many papers regarding LPS containing a novel lipid A structure which is composed mainly of 2,3-diamino-2,3dideoxy-D-glucose (DGA). ${ }^{5}$ Kasai et al. showed that lipid A containing DGA as well as the usual lipid A is able to induce the production of tumor necrotizing factor. $\left.{ }^{6}\right)$ Examination of the biological activity of lipid A analogs possessing other types of sugars as the backbone sugar may be useful for the development of new immunomodulators.

\section{References}

1) C. R. H. Raetz, Annu. Rev. Biochem., 59, 129 (1990).

2) M. Matsuura, Y. Kojima, J. Y. Homma, Y. Kubota, A. Yamamoto, M. Kiso, and A. Hasegawa, FEBS Lett., 167, 226 (1984); Y. Kumazawa, M. Matsuura, J. Y. Homma, Y. Nakatsuru, M. Kiso, and A. Hasegawa, Eur. J. Immunol., 15, 199 (1985); T. Shimizu, S. Akiyama, T. Masuzawa, Y. Yanagihara, S. Nakamoto, T. Takahashi, K. Ikeda, and K. Achiwa, Chem. Pharm. Bull., 33, 4621 (1985); idem, ibid., 345169 (1986); T. Shimizu, S. Akiyama, T. Masuzawa, Y. Yanagihara, S. Nakamoto, and K. Achiwa, Infect. Immun., 55, 2287 (1987); T. Shimizu, T. Masuzawa, Y. Yanagihara, C. Shimizu, K. Ikeda, and K. Achiwa, FEBS Lett., 228, 99 (1988); T. Shimizu, T. Masuzawa, Y. Yanagihara, S. Nakamoto, H. Itoh, and K. Achiwa, J. Pharmacobio-Dyn., 11, 512 (1988); T. Shimizu, Y. Ohtsuka, T. Masuzawa, Y. Yanagihara, H. Itoh, S. Nakamoto, and K. Achiwa, Mol. Biother., 2, 110 (1990); T. Shimizu, Y. Ohtsuka, Y. Yanagihara, H. Itoh, S. Nakamoto, and K. Achiwa, Int. J. Immunopharmac., 13, 605 (1991).

3) S. Nakamoto, T. Takahashi, K. Ikeda, and K. Achiwa, Chem. Pharm. Bull., 33, 4098 (1985).

4) O. Westphal, O. Lüderitz, and F. Bister, Z. Naturforsch., 7b, 148 (1963).

5) J. Roppel, H. Mayer, and J. Weckesser, Carbohydr. Res., 17, 93 (1975); J. Weckesser, G. Drews, and H. Mayer, Annu. Rev. Microbiol., 33, 215 (1979); H. Mayer, E. Bock, and J. Weckesser, FEMS Microbiol. Lett., 17, 93 (1983); R. Weisshaar and F. Lingens, Eur. J. Biochem., 137, 155 (1983); S. G. Wilkinson and D. P. Taylor, J. Gen. Microbiol., 109, 306 (1987); N. Kasai, S. Arata, J. Mashimo, Y. Akiyama, C. Tanaka, K. Egawa, and S. Tanaka, Biochem. Biophys. Res. Commun., 142, 972 (1987); A. Yokota, M. Rodriguez, Y. Yamada, K. Imai, D. Browiak, and H. Mayer, Arch. Microbiol., 149, 106 (1987); J. Weckesser and H. Mayer, FEMS Microbiol. Rev., 544, 143 (1988).

6) S. Arata, K. Nakaya, H. Furuhashi, Y. Nakamura, T. Hirayama, J. Mashimo, and N. Kasai, Jpn. J. Cancer Res., 79, 626 (1988). 